\title{
The Role of the Campus Environment in Fostering a Sense of Mattering among Postgraduate Commuter Students in Botswana
}

\author{
Dawn E. Lyken-Segosebe ${ }^{1}$, Mbiganyi Moremi ${ }^{1}$, Mbizo Mafuraga ${ }^{1}$ \& Benjamin M. Mogotsi ${ }^{1}$ \\ ${ }^{1}$ Centre for Business Management, Entrepreneurship, and General Education, Botswana International University of \\ Science and Technology \\ Correspondence: Dawn Lyken-Segosebe, Centre for Business Management, Entrepreneurship, and General \\ Education, Botswana International University of Science and Technology, Private Bag 16, Palapye, Botswana. \\ E-mail: segosebed@biust.ac.bw
}

Received: August 23, 2019

Accepted: September 13, $2019 \quad$ Online Published: September 19, 2019

doi:10.5430/ijhe.v8n6p1

URL: https://doi.org/10.5430/ijhe.v8n6p1

\begin{abstract}
Commuter students can be found at practically every institutional type in higher education. Despite their increasing numbers as returning students to pursue Master's and $\mathrm{PhD}$ programs, little is known about postgraduate commuter students and their experiences at US and international universities. A mixed-methods embedded design was utilized to investigate whether and how postgraduate commuter students at a rural public research-intensive university in Botswana perceived they mattered or were marginal to their university. Findings revealed that the physical, human aggregate, organizational, and socially constructed environments of the university influenced perceptions of mattering among study participants. Postgraduate students perceived they did not matter to the university because of its focus on undergraduates, its approach to managing postgraduate education, its failure to provide postgraduate housing, and the cost and unavailability of transportation. However, the availability of a teaching assistantship and supervisors' interest and support fostered the sense among these students that they were receiving attention, considered important, depended on, and empathized with.
\end{abstract}

Keywords: mattering, marginality, commuter students, postgraduate student experience, campus environments

\section{Introduction}

The physical environment of the campus, whether natural or constructed, shapes behavior by permitting certain kinds of activities while limiting - or making impossible - others (Kinzie \& Mulholland, 2007, p. 105).

Commuter students do not live in institutionally-owned or -operated housing on-campus (Jacoby \& Girrell, 1981). They live either within walking distance or kilometers from a university - and may commute to school by car, train, bus, biking, walking or other means (Jacoby \& Girrell, 1981). They can be found at practically every institutional type in higher education (Jacoby, 2000). Within the USA, while undergraduate commuter students account for over 80 percent of today's college students, the extant literature suggests that they often experience a sense of not mattering to their institutions (Horn \& Nevill, 2006).

Mattering is defined as "the feeling that others depend on us, are interested in us, are concerned with our fate, experience us as an ego-extension [which] exercises a powerful influence on our actions" (Rosenberg \& McCullough, 1981, p. 165). Mattering is viewed as a form of external validation by others at an interpersonal level (e.g. by professors and peers), or at a society level (e.g. by the university) (Rosenberg \& McCullough, 1981). Perceptions of being marginal exist as the polar opposite to feelings of mattering (Schlossberg, 1989). Jacoby (1989) posits that commuter students have been marginalized by institutional history and institutional practice, an experience that has adversely impacted key markers of success for these students such as levels of learning, personal development, student satisfaction, and persistence. Among US undergraduate commuter students, the timing of classes and campus events, opening hours of campus offices, and problems encountered in relation to housing, parking, and transportation around campus are just some of the issues that foster a sense of being marginal to the institution (Jacoby, 1989). 
Commuter students have historically been associated with undergraduates particularly since the advent of Arthur Chickering's (1974) book, Commuting versus Resident Students. Little is known about postgraduate commuter students and their experiences at US and international universities. This is despite the fact that postgraduate students constitute an increasing number of commuter students returning to campuses to pursue Master's and PhD programs. The purpose of this study was to explore whether and how postgraduate commuter students at a rural public research-intensive university in Botswana perceived they mattered or were marginal to their university. In particular, the study sought to explore students' perceptions of specific acts, practices, behaviors, and reactions they received while on campus, and whether those feelings connoted a sense of receiving attention, and that they were important, depended upon, and empathized with. The study also sought to identify the specific reasons for the perceptions of mattering or marginality, and what institutional actions were necessary to improve their sense of mattering. This study was in line with Strange \& Banning's (2015, p. x) assertion that student behavior, whether in the form of leaving or persisting, must be examined in terms of characteristics of the person and characteristics of the environment. Accordingly, three research questions drove this study:

1. To what extent do postgraduate commuter students perceive they matter to the university?

2. Does the perception of postgraduate commuter students that they matter generally, receive attention, are important, depended on, and empathized with by their university, differ by gender, degree level, academic program and having an assistantship?

3. How does the campus environment foster a sense of mattering or marginality among postgraduate commuter students?

This study breaks new ground with regards to studies that specifically examine the postgraduate student experience in Botswana. It contributes to the body of knowledge on what campus environmental issues matter to success for postgraduate commuter students. The study also informs on university practices and interventions that can improve postgraduate students' campus experiences as commuter students and their sense of mattering to the institution.

\section{Conceptual Framework}

The study derived its conceptual framework from conceptions of Mattering (Rosenberg \& McCullough, 1981; Schlossberg, 1989), and the Campus Environment (Strange \& Banning, 2001, 2015).

\subsection{Mattering}

Rosenberg \& McCullough (1981) considered mattering as a person's subjective belief or "feeling that others depend on us, are interested in us, are concerned with our fate, experience us as an ego-extension [which] exercises a powerful influence on our actions" (Rosenberg \& McCullough, 1981, p. 165). Mattering influences a person's behavior and psychological well-being and was initially conceived as having three dimensions - attention, importance, and dependence. Attention is considered "the most elementary form of mattering" and described as "the feeling that one commands the interest or notice of another person" (Rosenberg \& McCullough, 1981, p. 164). Importance is described by the two researchers (p. 164) in this way: "To believe that the other person cares about what we want, think, and do, or is concerned with our fate, is to matter." The third dimension, Dependence, is described as the feeling that we matter because others depend on us or need us (Rosenberg \& McCullough, 1981).

Schlossberg (1989) extended the concept of mattering to the student affairs field and added two dimensions of mattering - ego-extension and appreciation. The dimension of Appreciation relates to feeling acknowledged and valued. Ego-extension is defined as "the feeling that other people will be proud of our accomplishments or saddened by our failures" (Schlossberg, 1989, p. 10). Schlossberg (1989) also introduced the concept of marginality as a feeling opposite to that of mattering. In her view, one could feel marginal in one situation and feel that you matter in another.

\subsection{The Campus Environment}

Strange \& Banning's $(2001,2015)$ campus ecology model presents a conceptual understanding of the campus environment and its influence on students' behavior and success. According to the two researchers, the campus environment has four components - the physical, human aggregate, organizational, and perceptual or socially constructed environments. Strange \& Banning's physical environment relates campus design and space to students' behavior and experiences on campus. Students develop a sense of place as they interact with the natural and built aspects of the campus environment, its architectural features (e.g. shape and design of residence halls, functionality of buildings and offices, accessibility of buildings and parking lots, etc.), landscape features (e.g. open spaces, shaded lawns, etc.), artifacts of material culture that adorn a campus, and other functional and cultural characteristics 
of a campus (Strange \& Banning 2001, p. 13). As part of campus' human aggregate environment, people, their demographic and typological characteristics (e.g. age, gender, personalities, learning styles, etc.), and behaviour create the dominant features that characterize a campus environment (Strange \& Banning, 2001, p. 6).

Strange \& Banning's (2001) organizational environment focuses on how an institution's environment is constructed to achieve its goals. Organizational structures created to meet those goals may be based on complexity (e.g. work organized by divisions, departments, academic programs), centralization/decentralization of decision-making, formalization (e.g. rules and regulations), and other institutional priorities. The perceptual or socially constructed environment reflects the subjective views, experiences and social constructions of those inhabiting that environment. It reflects collective perceptions of the campus culture (e.g. traditions, values, practices, policies, socially shared perspectives), the social climate (e.g. relationships/involvement within the setting), and the community setting.

Based on the above, this study's conceptual framework proposed that a university's physical, human aggregate, organizational, and socially constructed environments had the capacity to foster perceptions of mattering among its postgraduate commuter students.

\section{Literature Review}

\subsection{Commuter Students and Their Needs}

A review of the peer-reviewed literature found no study that examined the perceptions of postgraduate commuter students on mattering or marginality to their institutions. While the literature on commuter students provides a profile of undergraduate commuter students, many aspects of this profile are equally relevant to postgraduate students. For instance, postgraduate commuter students fit Keeling's $(1999$, p. 4) description of commuter students as having multiple roles, that is, “. . 'Student' is only one identity for people who are also employees, wage workers, opinion leaders or followers, artists, friends, children ... parents, partners, or spouses."

Postgraduate commuter students' multiple roles may threaten their academic and social integration within the university. Like undergraduates, these students face several challenges and needs. Jacoby \& Garland (2004, p. 64) state, "The most obvious concerns that commuter students share are those related to transportation: parking, traffic, fixed transportation schedules, inclement weather, vehicle maintenance, transportation costs, and locating alternative means of transportation when their primary means fails." Sense of belonging is also a critical need of commuter students. Jacoby \& Garland (2004) state that students who commute often lack a sense of belonging to or of feeling wanted by the institution. Universities may not provide basic facilities, such as lockers and lounges, which allow students to feel physically connected to campus. The two researchers state there might be inadequate opportunities for commuter students to develop relationships with faculty, staff, and peers and as such, may not feel connected to "a place where they have no significant relationships" (Jacoby \& Garland, 2004, p. 65).

\subsection{The Campus Environment}

A review of the peer-reviewed literature found no study that examined the perceptions of postgraduate commuter students on how the campus environment affected their sense of mattering or marginality to their institutions. However, for students generally, Kuh, Kinzie, Buckley, Bridges, \& Hayek (2006, p. 40) found that "the single best predictor of student satisfaction with college is the degree to which they perceive the college environment to be supportive of their academic and social needs." Institutions vary considerably as to the degree to which their physical and social environments foster or are congenial to student success (Berger \& Milem 2000; Pascarella \& Terenzini 2005). For example, some institutions encourage student-faculty interaction by creating well-equipped group study space proximal to faculty offices, thereby increasing the likelihood of spontaneous interactions between students and faculty (Kuh, Kinzie, Schuh, \& Whitt, 2005). Some institutions create a strong "sense of place" by connecting campus architecture and design to meaningful experiences and memories of activities such as placing student residences in close proximity to academic buildings to promote interactions with students (Kuh, 2000; Kuh et al., 2005). Understanding how various groups of students perceive and react to the physical environment should be an essential step in any effort to enhance student satisfaction and success (Banning \& Cunard, 1996).

\section{Method}

A mixed-methods embedded design was utilized on the assumption that using both quantitative and qualitative methods "provide a better understanding of the research problem and question than either method by itself" (Creswell, 2014, p. 565). The sole reliance on a quantitative study using a survey instrument was considered inadequate by the study's researchers given low prior survey participation rates among the institution's student population. A survey research design was implemented in the quantitative phase to answer research questions \#1 and \#2. Research question \#3 was addressed during the study's concurrent qualitative phase that was specifically 
designed to elaborate on and add nuance to findings of the quantitative phase. A case study methodology was implemented given the aim to understand "the why" behind the perspectives of these students. Institutional ethics approval and a research permit were acquired prior to commencement of the study.

\subsection{Procedures - Quantitative Study}

\subsubsection{Study Sample and Data Collection}

An invitation to complete an online Mattering Survey in Google Forms (and two follow-up emails) were sent to the entire postgraduate student population comprised of 262 Master's and PhD students enrolled during the 2018-2019 academic year. The survey comprised 34 questions modified from the University Mattering Scale (UMS) developed by Elliott, Kao, \& Grant (2004), and France's (2011) Revised University Mattering Scale (RUMS). Questions related to the four dimensions of mattering - attention, importance, dependence, and ego-extension but adopted the terminology used by Elliott et al. (2004) who replaced the "attention" and "dependence" dimensions with "awareness" and "reliance" respectively. A check of the internal consistency of the 34 survey items yielded a Cronbach's alpha coefficient of 0.76. Participants to the Mattering Survey responded to the questions using the 4-point Likert scale 1= strongly disagree, 2 = disagree, 3 = agree, $4=$ strongly agree. The fifth "neutral" scale on the UMS and the "disagree slightly" and "agree slightly" scales on the RUMS were excluded by study researchers to avoid their inherent ambiguities. Table 1 indicates the questions on the study's Mattering Survey and their summary statistics.

Table 1. Mattering Survey Questions

\begin{tabular}{|c|c|c|c|}
\hline \# & Question & Mean & $\begin{array}{l}\text { Standard } \\
\text { Deviation }\end{array}$ \\
\hline 1. & People in the [University X] community pay attention to me. & 2.29 & 0.61 \\
\hline 2. & When people at [University X] need help, they come to me. & 2.73 & 0.73 \\
\hline 3. & I have noticed that people at [University X] will take the time to help me. & 2.55 & 0.75 \\
\hline 4. & $\begin{array}{c}\text { My successes are a source of pride to the people of the [University X] } \\
\text { community. }\end{array}$ & 2.57 & 0.82 \\
\hline 5. & The majority of people in the [University $\mathrm{X}$ ] community recognize me. & 2.12 & 0.60 \\
\hline 6. & People in the [University X] community are concerned about my needs. & 1.73 & 0.57 \\
\hline 7. & $\begin{array}{l}\text { There is no one at [University X] who would share in my excitement about my } \\
\text { accomplishments.* }\end{array}$ & 2.61 & 0.79 \\
\hline 8. & Most people in the [University X] community seem to notice me. & 2.65 & 0.95 \\
\hline 9. & $\begin{array}{c}\text { People in the [University X] community count on me to be there in times of } \\
\text { need. }\end{array}$ & 2.69 & 0.74 \\
\hline 10. & $\begin{array}{l}\text { There are people in the [University X] community who react to what happens to } \\
\text { me in the same way they would if it happened to them. }\end{array}$ & 2.53 & 0.84 \\
\hline 11. & $\begin{array}{l}\text { When I have a problem, people in the [University X] community usually don't } \\
\text { want to hear about it.* }\end{array}$ & 2.57 & 0.84 \\
\hline 12. & Most people in the [University X] community seem to notice when I come or go. & 2.35 & 0.80 \\
\hline 13. & I know people in the [University $\mathrm{X}]$ community are sincerely interested in me. & 2.00 & 0.46 \\
\hline 14. & $\begin{array}{l}\text { Often, the people in the [University X] community trust me with things that are } \\
\text { important to them. }\end{array}$ & 2.61 & 0.73 \\
\hline 15. & $\begin{array}{l}\text { If I had a setback, there would be no one at [University X] who would share in } \\
\text { my feelings of unhappiness.* }\end{array}$ & 2.45 & 0.79 \\
\hline 16. & There are people at [University X] who give me advice when I need it. & 2.92 & 0.81 \\
\hline 17. & It is hard for me to get attention from people of the [University X] community.* & 2.45 & 0.77 \\
\hline 18. & $\begin{array}{l}\text { There are people in the [University X] community who would be sad if they } \\
\text { knew I was sad. }\end{array}$ & 2.57 & 0.84 \\
\hline 19. & $\begin{array}{c}\text { I am not someone the people in the [University X] community would turn to } \\
\text { when they need something.* }\end{array}$ & 2.71 & 0.82 \\
\hline 20. & Some people at [University X] would feel as enthusiastic as I would, if I were to & 2.84 & 0.69 \\
\hline
\end{tabular}


21. Sometimes at [University X], I feel as if I were invisible.*

22. There are people in the [University X] community who would also experience my disappointment if I didn't reach my full potential.

24. The people in the [University X] community are usually aware of my presence.

25. People in the [University X] community are invested in my life.

26. Quite a few people in the [University X] community look to me for advice on issues of importance.

27. People in the [University $\mathrm{X}]$ community tend to remember my name.

28. People in the [University $\mathrm{X}$ ] community don't care about my personal welfare.*

30. People in the [University X] community generally know when I am around.

34. If I were not a [University X] student, the [University X] community would suffer.

Note. $*$ - reverse scored

In preparation for data analysis, the eight negatively worded questions (Questions 7, 11, 15, 17, 19, 21, 23, 28) were reverse scored so that higher scores indicated higher levels of university mattering. The Mattering variable was operationalized from the four dimensions of mattering which were in turn, operationalized from the following survey questions:

Awareness: Questions 1, 5, 8, 12, 17, 21, 24, 27, 30

Importance: Questions 3, 6, 11, 13, 16, 25, 28, 31

Reliance: Questions 2, 9, 14, 19, 23, 26, 29, 32, 34

Ego-Extension: Questions 4, 7, 10, 15, 18, 20, 22, 33

\subsubsection{Data Analysis}

A descriptive analytical strategy was adopted and t-tests utilized to examine mean differences among respondents. The data were analyzed using STATA software.

\subsection{Procedures - Qualitative Study}

\subsubsection{Study Sample, Site and Data Collection}

The instrumental case or unit of analysis was the population of Master's and $\mathrm{PhD}$ students enrolled at a rural research-intensive university in Botswana. This group of 262 students all lived off-campus and therefore constituted commuter students. The University was the natural setting for this study. The study site was located on over five thousand acres of land at the extreme end of a village. A $4-\mathrm{km}(2.5 \mathrm{mile})$ access road connected the campus to the main taxi/bus route and nearest housing area. The nearest shopping centre was $10 \mathrm{kms}$ (6 miles) from campus. The institution had been in operation at this site for less than five years and had an enrollment size that characterized it as small (fewer than 2,500 students). On-campus housing was provided only to undergraduate students.

The data for the case study were collected from two sources. First, internal institutional documents in the form of tracer studies of past university graduates were examined for accounts of postgraduate student experiences. These accounts provided background information and input for the development of the focus group protocol. Secondly, a focus group meeting was conducted with 21 postgraduate students. Both convenience and purposive sampling were utilized. Invitation letters were emailed to 15 Science and 15 Engineering postgraduate students. Emailed letters addressed the issue of confidentiality and anonymity. Students were assured that pseudonyms would be used to describe them in any publication. The meeting was conducted by the four study researchers for better control and reliability in the questioning process. The protocol included guiding questions related to the four dimensions of mattering. After participants gave informed consent, comments were digitally recorded and later transcribed. Field, theoretical, and personal notes were created to assist subsequent triangulation of findings. 


\subsubsection{Data Analysis}

Open, axial, and selective coding (Strauss \& Corbin, 1998) were used to analyze the transcription data. The iterative process of "constant comparison" generated themes related to the aspects of the campus environment that fostered a sense of mattering and marginality (Strauss \& Corbin, 1990). Rigor was assured through the incorporation of procedures to address credibility and dependability (Lincoln \& Guba, 1985). Data was triangulated by gathering information from multiple sources (e.g. field notes by all four researchers and a verbatim transcript), and member checks involving four teaching assistants who checked narratives and the analysis of comments for accuracy. In addition, thick description was utilized in the analysis to allow the reader to envision the perceptions of study participants.

\section{Findings}

\subsection{Sample Profile}

\subsubsection{Profile - Quantitative Study}

Forty-nine (49) of the 262 postgraduate student population, responded to the Mattering Survey. This yielded a low response rate of nineteen (19) percent.

Table 2. Descriptive Statistics for Sample - Quantitative Study

\begin{tabular}{cccc}
\hline Variable & $\boldsymbol{N}$ & Mean & Standard Deviation \\
\hline Female & 49 & 0.45 & 0.50 \\
Degree level (PhD) & 49 & 0.25 & 0.44 \\
Academic program (Science) & 49 & 0.67 & 0.47 \\
Teaching Assistant & 49 & 0.84 & 0.51
\end{tabular}

Table 2 displays summary statistics for the demographic profile of Survey respondents. Respondents were on average male (55 percent), aged 24-29 years (74 percent), pursuing a Master's degree (75 percent), and employed as teaching assistants on campus (84 percent). Most of the analytical sample were enrolled in the Faculty of Science (67 percent) with just under 20 percent of respondents pursuing the MSc degree in Computer Science.

On average, most of the sample earned P 5000-P 7500 (approximately US\$ 500-750) per month. Most lived 10-15 kms (6-9 miles) from the institution, took 25-30 minutes to get to campus mostly by taxi and hitchhiking, and spent between P400-P600 (approximately US\$40-60) per month on transport. Most lived in one-bedroom Bachelor Pads with no air-conditioning. Rent ranged between P1000-P1800 (approximately US\$100-180) per month

\subsubsection{Profile - Qualitative Study}

Qualitative data were collected from 21 postgraduate students who, out of the invited 30 students, attended the focus group meeting. Thirteen (13) Science and eight (8) Engineering postgraduates responded to the invitation. Their demographic profile was as shown in Table 3. The sample was broadly similar to that of the quantitative study in that most were from the Faculty of Science, pursuing the MSc Computer Science, and worked as teaching assistants. However, this sample was mostly female, took a longer time (over 30 minutes) to commute to campus, and got there mostly by hitchhiking. 
Table 3. Descriptive Statistics for Sample - Qualitative Study

\begin{tabular}{|c|c|}
\hline Variable & $\begin{array}{c}\text { Proportion } \\
(N=21)\end{array}$ \\
\hline \multicolumn{2}{|l|}{ Gender: } \\
\hline Male & 0.38 \\
\hline Female & 0.62 \\
\hline \multicolumn{2}{|l|}{ Degree Level: } \\
\hline $\mathrm{PhD}$ & 0.14 \\
\hline MSc & 0.57 \\
\hline MEng & 0.29 \\
\hline \multicolumn{2}{|l|}{ Program Area: } \\
\hline $\mathrm{PhD}$ Computer and Telecommunications Engineering & 0.05 \\
\hline PhD Computer Science & 0.09 \\
\hline MSc Computer Science & 0.43 \\
\hline MSc Information Systems & 0.05 \\
\hline MSc Geological Science & 0.05 \\
\hline MSc Statistics & 0.05 \\
\hline MEng Geological Engineering & 0.14 \\
\hline MEng Computer and Telecommunications Engineering & 0.14 \\
\hline \multicolumn{2}{|l|}{ Work Status: } \\
\hline Teaching Assistant & 1.0 \\
\hline \multicolumn{2}{|l|}{ Commuting Time to University: } \\
\hline 10 mins $-<15$ mins & 0.14 \\
\hline 15 mins $-<20$ mins & 0.09 \\
\hline 20 mins $-<25$ mins & 0.19 \\
\hline 25 mins $-<30$ mins & 0.14 \\
\hline 30 mins and over & 0.43 \\
\hline \multicolumn{2}{|l|}{ Mode of Commute: } \\
\hline Hitchhiking & 0.48 \\
\hline Car & 0.33 \\
\hline Taxi & 0.19 \\
\hline
\end{tabular}

\subsection{Findings by Research Question}

Participants' views were sought on whether and how as postgraduate commuter students they mattered or were marginal to their university. Research questions \#1 and \#2 were addressed in the quantitative phase of the study while question \#3 was addressed in the qualitative phase.

\section{Research Question One}

To what extent do postgraduate commuter students perceive that they matter to the university?

Table 4. Descriptive Statistics for Mattering and the Four Dimensions of Mattering

\begin{tabular}{cccccc}
\hline Variable & $\boldsymbol{N}$ & Mean & $\begin{array}{c}\text { Standard } \\
\text { Deviation }\end{array}$ & Min & Max \\
\hline Awareness & 49 & 2.29 & 0.48 & 1 & 4 \\
Importance & 49 & 2.02 & 0.40 & 1 & 4 \\
Reliance & 49 & 2.65 & 0.45 & 1 & 4 \\
Ego-Extension & 49 & 2.78 & 0.48 & 1 & 4 \\
Mattering & 49 & 2.18 & 0.39 & 1 & 4 \\
\hline
\end{tabular}


Table 4 displays summary statistics for the mattering variables. Participants responded to Survey questions using the 4-point Likert scale $1=$ strongly disagree, 2 = disagree, 3 = agree, $4=$ strongly agree. The mean value for overall mattering (2.18) suggested that these postgraduate commuter students did not perceive they mattered to the university. In particular, they disagreed with statements suggesting that they commanded the university's interest (importance) and that the university cared about what they wanted, thought or did (awareness). However, this group of students perceived that the university depended upon and needed them (reliance) and that persons would be proud of their accomplishments and saddened by their failures (ego-extension).

\section{Research Question Two}

Does the perception of postgraduate commuter students that they matter generally, receive attention, are important, depended on, and empathized with by their university, differ by gender, degree level, academic program or having an assistantship?

Table 5 indicates means for the mattering variables by gender, degree level, academic program and having an assistantship. Independent t-tests revealed that the perception of overall mattering was higher among male than female students. The perception of being depended on (reliance) was higher among males and for students with teaching assistantships. Students enrolled on Master's programs were more inclined than their $\mathrm{PhD}$ counterparts to feel that they were empathized with (ego-extension). No statistical differences in overall mattering and its dimensions were discerned between engineering and science students, or for the awareness and importance dimensions by gender, degree level, academic program and having an assistantship.

Table 5. T-test results for differences in Mattering by Gender, Degree Sought, Program and Assistantship

\begin{tabular}{cccccc}
\hline & Mattering & Awareness & Importance & Reliance & Ego-Extension \\
\hline Gender & & & & & \\
Male & 2.59 & 2.52 & 2.44 & 2.26 & 2.15 \\
Female & 2.39 & 2.26 & 2.25 & 2.0 & 2.0 \\
T-statistic & $1.97^{*}$ & 1.92 & 1.66 & $2.04^{*}$ & 0.97 \\
Degree sought & & & & & \\
PhD & 2.36 & 2.31 & 2.19 & 2.08 & 1.83 \\
Masters & 2.54 & 2.43 & 2.41 & 2.16 & 2.16 \\
T-statistic & 1.42 & 0.74 & 1.68 & 0.52 & $2.08^{*}$ \\
Program & & & & & 2.19 \\
Engineering & 2.52 & 2.39 & 2.36 & 2.13 & 2.03 \\
Science & 2.49 & 2.40 & 2.35 & 2.15 & 0.97 \\
T-statistic & 0.25 & -0.08 & 0.06 & -0.19 & \\
On-Campus & & & & & 2.11 \\
Job & & 2.46 & 2.36 & 2.18 & 2.0 \\
Assistantship & 2.51 & 2.19 & 2.32 & 2.13 & -0.57 \\
No & 2.46 & -1.70 & -0.23 & $-1.98^{*}$ & \\
Assistantship & & & & & \\
T-statistic & -0.38 & & & & \\
\hline Nob & & & & & \\
\hline
\end{tabular}

Note. ${ }^{*} \mathrm{p}<.05, * * \mathrm{p}<0.01,{ }^{* * *} \mathrm{p}<0.001$

\section{Research Question Three}

How does the campus environment foster a sense of mattering or marginality among postgraduate commuter students?

Twenty-one (21) postgraduate commuter students participated in a focus group meeting. Three themes emerged as central to framing students' perception of the relationship between the campus environment and mattering at their rural public research-intensive university. The themes were: 1) specific individuals encourage a sense of connection 
to the university, 2) the availability/non-availability of a teaching assistantship fostered the perception of mattering/marginality, and 3) the overall perception of not mattering to the university.

The most effective technique for presenting the study's findings is to let the participants' narratives (their voices) tell the story of their experiences.

\section{Role of Specific Individuals in making a Connection to Campus}

Transcription data revealed the unanimous contention among participants that they mattered to their research supervisors and the lecturers for whom they were teaching assistants. According to Bontle:

The people who care, the people who feel you matter, are your supervisors. The same lecturer you TA for is the one who cares, we matter to them. They ask, "are you ok?" After class they ask, "how's your school work?" "How's your thesis going?"

Students perceived that these individuals cared about both the progress of their studies as well as their social welfare. Naledi stated that:

My thesis supervisor is very encouraging. He's a pusher and he motivates. When school opens every semester he will be really concerned like, "have you gotten your TAship?" "are you happy with the subject you're teaching?" and stuff like that. That is very encouraging. He knows that with TAship when you're settled economically you can focus on your work.

\section{Role of the Teaching Assistantship}

All participants in the focus group were teaching assistants. Based on the discussion, the assignment of a teaching assistantship created a feeling of mattering and belonging to the institution for this group of students. This on-campus work assignment positively impacted the students in two ways. First, by providing students with a physical space, the teaching assistantship created a feeling of connection between these commuter students and the institution. Of the 21 participants, 6 participants had offices. Others had access to a table and chair in open areas they referred to as "bullpens." Participants explained that seating arrangements depended on the interest of Heads of Department and Supervisors. Otherwise where you sat "It is not allocated to you, you just take it." However, students indicated that seating and facilities could be improved. Most did not have access to a cabinet or locker to store materials and personal belongings. Available lockers could not be accessed because previous university students had not returned keys at graduation.

Secondly, the teaching assistantship appeared to have a positive impact on these commuter students by fostering the sense that they were important and depended on by undergraduate students. According to Kagiso,

Being a TA, you know you matter to students when they come to you and ask for help. They depend on us. We mentor them in spite of our troubles, we teach them. We stay after hours to help them, commit our time to tutor them.

In contrast, the perception of being marginal to the institution was linked to not receiving or losing a teaching assistantship. The international students in the group recalled the situation of a student for whom the challenges of meeting living expenses forced her to return to her home country after her department failed to renew her assistantship. Local students also departed the village after failing to obtain assistantships. Modise informed:

It's a challenge for students who are not Teaching Assistants. Those people rarely come to school. Only when they need to talk to their supervisors. They've gone back home.

\section{Overall Perception of Not Mattering}

Students attending the focus group meeting were unanimous in their contention that they did not matter to their institution as a whole. They posited four reasons for this perception. The first two reasons were general while the remaining two were specific to their classification as commuter students. First, the students considered the university as having a primary focus on undergraduate students and neglecting to give the same attention to its postgraduate students. Dineo stated:

[X University] does not care about anything to do with us. What they care about is what matters to them. There's a lot more focus on undergraduates.

He suggested that the lower attention received might be attributed to the relatively smaller size of the postgraduate student population. 
The second reason given was [X University's] approach to managing postgraduate education. It was Mpho's opinion that the current economic state of the country and economic backgrounds of the institution's students were ignored in that approach. For her:

I think [X University] is in denial. The way they want to run postgraduate life is like they want to run things the way things are run in first world countries. They tend to deny that actually we are in a third world country. When you're a postgraduate student they expect that you've been saving up for your studies all along. ...They expect that you're going to come with some sort of sponsorship, You can't run a university in a third world country the way things are run elsewhere.

Modise noted that students from disadvantaged backgrounds were placed in a financial bind because the university's village locality offered no employment prospects, the nearest town where employment might be found was over 150 $\mathrm{km}$ (over 100 miles) away, and "on top of that" the university did not permit part-time study. He said that students were therefore financially dependent on the university. Modise recalled the frustration experienced at an all-students meeting with university management:

I got a clear introduction to how [X University] cares for its postgraduate students. We were at the hall with elders [university management] and new students asked whether you can do your Master's part-time at [X University]. And the answer was "no". So, you have to totally be here. And the next question asked was "When are we getting our TAships because it is orientation day and we haven't gotten our TAship yet?" The answer given was "when you come for your Masters or PhD everything is totally up to you. TA ship is not a right, it is a privilege." So, you come here, you study full-time and the condition is that you cannot study part-time. You cannot work and the school is telling you that we have no obligation to offer you any means of sustaining yourself. That clearly shows that you're on your own here.

Neo stated that the university's approach to postgraduate students and focus on undergraduate students ignored the role postgraduate students played in terms of research. He said, "I believe this institution was established to drive research not to be a duplicate of the teaching institutions, so without us the researchers really there is no [X University]." He was of the opinion postgraduate students were enhancing the university's reputation by identifying important research topics, conducting "first class" research and driving the progress of their supervisors' research. However, the limited provision of research funding and facilities was indicative of the university not considering postgraduate students important to its research mission.

Participants also provided two commuter specific reasons for not mattering to [X University]. First, they unanimously considered the university's failure to provide postgraduate housing as evidence that the university did not care about them. International participants recalled how the university's brochure had inaccurately suggested that on-campus housing would have been provided. Students gave several accounts of their off-campus living experiences with several describing being targeted for higher-than-market rents and crime. According to Thabo,

The housing here, the rent is too high especially if they hear you are from [X University]. They think you're an employee here so they will just tell you ridiculous prices just for one bedroom. And you have to choose carefully when you're looking for accommodation in [village ward]. Sometimes during December you go home. Imagine you're leaving your stuff there where there's thieves around. It's not safe.

Modise noted that the university's location in a village was unique and presented many challenges for postgraduate students. Agreeing with him, Naledi described the effects of not belonging or originating from the village. She said villagers perceived that "everyone" associated with [X University] occupied high income levels. She said:

When choosing a place to stay you have to be careful. We stay in [village ward] because the rent is mostly better. The problem with staying in certain parts of [village ward] is that you stick out like a sore thumb. You're an outlier because you're different. People there are unemployed and everyday you walk out of school at 7 p.m. and you're passing them with your laptop. You automatically feel like a target. Every morning you get up and go outside the gate and you're dressed differently. So, where you stay can make you feel very uncomfortable. You become a target for thieves. When you move in, people in the whole village will know that a [X University] student is living there. Your neighbour knows so everyone knows. And in the mornings people will knock on your door. They want to do your washing, they want to clean your house, they want to clean your yard. They knock continuously.

Students recounted how off-campus living in the village exposed them to crime. Some students' apartments were burglarized while they were away on campus or during holidays. According to Kagiso, 
You just become an outlier especially if you choose these places around [X University]. At one time I wanted to take a walk because you find yourself just alone the whole day in your house on a Saturday. I just wanted to go out and get some air. It was about 6 p.m. So, when I was walking I met some guys. They asked for two Pula from me but I told them I don't have two Pula. They just laughed and passed by. Then one told the others "Let's rob this guy." Can you believe it? They were just saying it openly. Then another one said "No, it's still light." If it was dark, aah! They would've taken everything.

Participants explained that they mostly worked on their research and thesis preparation at night because of the obligations of their teaching assistantships during the day. Bontle, one of the female students, shared her experience going home at night:

You place a school very, very, far, in the middle of the village and we use your own transport to get to school. I drive to school but the problem is I have to pass the bar in [village ward] where there's a [speed] hump. It is not safe to leave school at night. When I slow down at the [speed] hump they always try to open my car doors especially after midnight. [X University] should open vacant rooms so that I can just take a rest when I finish my work at 3 a.m. I can leave at 5 am to refresh, have a shower and return to school.

The second commuter-specific reason for feeling marginal to [X University] was the cost and unavailability of transportation. Students indicated that the transportation issue severely impacted them as commuters and restricted their time on campus. According to Modise,

The biggest challenge for me as a commuter is the cost of living. And then you add transport cost for getting to school, transport cost for buying groceries, transport cost for special occasions in school like when you have to invigilate and come to school at night. You're not going to get a special [taxi] at night. And also when school is closed for semester break there are no students so hiking is a bit difficult. You have to rely on taxis but taxi drivers don't have the motivation to come to school because [X University] is too far. So the cost of living in terms of taxis gets higher when schools are closed.

Students indicated that they mostly got to campus by hitchhiking and relied on being offered rides from [X University's] staff. However, they noted that some staff members charged hitchhikers a P 5 (US\$ 0.50) fee from "the circle," an intersection that connects one the roads to the university with a main village road. Kagiso said:

They don't even tell you that they're going to charge until you get to [X University]!

There was consensus that taxi drivers conceived [X University's] students as being well-off financially and took advantage of the distance of the university from housing areas and village amenities. When a student rented a taxi to get to campus, it was not uncommon for taxi drivers to inform them that "if there's customers at the side of the road" the driver will stop to pick them up.

Khumo noted of taxi drivers: "if you're new to the place, they will have a field day with you." This statement resonated with participants who were international students. Kathryn stated:

They hear your accent and they will take advantage of you. We will call a special taxi to come collect us from school. Instead of charging the whole group a fee of 35 Pula, they will say each one of you have to pay 35 Pula instead. They don't even tell you until you get to where you are going. Then they say "you have to pay me. I brought you guys here."

\section{Students' Recommendations for the Institution}

Study participants recommended the construction of a postgraduate village on campus with provisions made for students with families. Alternatively, they proposed that the university provide its postgraduate students with free rental apartments in the village and a shuttle bus service. A night shuttle bus service was recommended because several students left campus around or after midnight. Students stated that many were forced to leave campus at 6 p.m. with university staff. According to Lesego, "we leave when the staff leaves because they are our rides."

Students recommended the creation of an on-campus taxi pick-up point in the form of an erected shelter or a shaded area. They also required the provision of shaded parking lots. Mpho stated that she sometimes spent the entire night working on campus. Each morning she would walk over to use the showers in the university's gym. Participants suggested that since postgraduate housing was not provided, the university should provide on-campus overnight facilities with shower facilities, and a postgraduate student lounge where they could take short naps and hangout. Naledi also suggested ".... a childcare centre for our kids. A lot of postgraduates struggle when their maids knock off, but there's no internet at home and you have to study." Students required the institution to provide after-hour access 
to printing facilities, food services after the campus restaurant closed at 7 p.m., and the reallocation of lockers after students graduated from the institution.

\section{Discussion and Conclusions}

Postgraduate commuter students at a rural public research-intensive university in Botswana completed an online Mattering Survey and participated in a focus group meeting designed to elicit their perceptions on whether they mattered or were marginal to their university. Evidence of both mattering and marginality were discerned. Associations could be made with all four components of Strange \& Banning's (2001, 2015) campus ecology model. Findings linked the physical, organizational, and socially constructed environments at [X University] to perceptions of being marginal to the institution. Students attributed this perception to the institution's focus on undergraduates, its approach to managing postgraduate education, its failure to provide postgraduate housing, and the cost and difficulties associated with commuting. The university's physical environment in particular - its village location, the absence of on-campus postgraduate housing and associated transportation challenges - shaped this perception. Focus group findings were consistent with Survey results including the low overall mean level of mattering, and findings regarding students' perceptions of not commanding the university's interest and importance. The university's organizational environment shaped the perception of marginality through its focus on undergraduate students and its decisions regarding the management of postgraduate education. These findings were consistent with perceptions obtained from the Survey that the university did not care about what these students wanted, thought or did.

However, some sense of mattering was discerned. The teaching assistantship was a specific aspect of the organizational environment at [X University] that fostered three dimensions of mattering - awareness, importance and reliance - among students. It made them feel instrumental to the learning process of undergraduate students as well as provided them with seating space. This was consistent with the Survey finding that students perceived the university depended upon and needed them. Furthermore, students experienced all four dimensions of mattering from the university's human aggregate and socially constructed environments through their relationships with, and the support, mentorship and interest received from their research supervisors and the lecturers for whom they were teaching assistants. Survey results indicated students' agreement with statements that there were persons on-campus who were proud of their accomplishments and saddened by their failures.

There were at least two limitations which potentially tempered the study's conclusions and impacted the generalizability of findings to all postgraduate students at the university under study. The first limitation related to the low number of responses to the Mattering Survey. This low survey response rate was not unexpected as study's researchers had observed low prior survey participation rates among the institution's student population. However, it had been assumed that postgraduate students would be more willing to give feedback on issues directly affecting them than undergraduates. With regards to institutional practice, it is therefore recommended that the university intentionally foster a culture among students regarding responding to surveys. The link between student survey findings and informed decision-making on important student-related matters such as teaching, research support, services and other areas should be established clearly and communicated early to all students beginning at new student orientation.

The second limitation related to the relatively lower participation rates to both the survey and the focus group meeting by Engineering postgraduate students. Invitation letters to the focus group meeting were emailed to 15 Science and 15 Engineering postgraduate students. Of the 30 invited students, 21 students - thirteen (13) Science and eight (8) Engineering postgraduates - responded to the invitation. This second limitation is muted however because it is unclear whether a different set of findings might have obtained from additional respondents pursuing Engineering qualifications. Concerted efforts should be made in future research studies to ensure a more balanced sample is obtained.

At least two conclusions may be drawn from Survey findings and the narratives of the postgraduate students who participated in this study. The first conclusion is overarching - a university's location matters. According to Strange \& Banning (2015, p. xi) "the capacity of any postsecondary institution to carry out its educational mission depends in part, on how well its principal features are understood and designed accordingly." While locating a university in a rural location has spatial advantages, prior assessment must be made of the capacity of that locality and its available services to accommodate students to whom the university does not provide housing or employment. Students' comments suggest that the village appeared unsuited socially, economically and infrastructurally to host the influx of institutional staff and students.

The second conclusion - that the provision of postgraduate apartments or other permanent arrangement is warranted relates to the challenges faced by these commuter students. Students' narratives described village housing as 
available only at high and variable cost. The related cost of transportation was prohibitive given the distance from the village to the institution and the fare gouging practices of taxi operators. The situation was compounded by students' own hitchhiking tendencies which rendered uneconomic the establishment of a regular bus or taxi route between the university and the village centre.

Study findings suggest two recommendations for institutional practice. The first recommendation emanates from the perceived treatment of postgraduate students. The management of postgraduate education should be consistent with an institution's mission, in this case its research mission. As producers and contributors to knowledge generation and dissemination through research or as teaching assistants, postgraduate students add value to a research-intensive university. Their contribution can be drawn from a 2014 Massachusetts Institute of Technology Faculty Newsletter Editorial on The Importance and Value of our Graduate Students that states:

... graduate students are key to our scientific and engineering productivity; they will be the coming generation of researchers and innovators; and they will be the mentors and instructors of further generations of young people...They are our skilled junior partners in carrying out experiments, making the measurements, developing new ideas and knowledge. Their research and their teaching also enrich the undergraduate curriculum and experience. (Kaufman, King, \& Verghese, 2014)

The second recommendation derives from the finding that not all students received teaching assistantships at the study site. The recommendation for the provision of financial assistance either in the form of teaching and/or research assistantships is important for two reasons. Students' narratives suggest their personal economic circumstances would hinder persistence in their postgraduate programs in the absence of funding. Furthermore, as on-campus work assignments, teaching and research assistantships represent important socialization and training tools for postgraduate students aspiring to join the professoriate in the future.

Commuter students have been marginalized by institutional history and practice (Jacoby, 1989), an experience that can adversely impact key markers of student success such as levels of learning, personal development, student satisfaction, and persistence. With their growing presence at today's higher education institutions, it is important that universities understand that even returning students at postgraduate level require supportive campus environments. Their academic and social integration at these institutions remain a challenge for administrators. Inquiry into how universities can foster a sense of mattering among commuter students, needs to be further explored to enable university administrators to identify what's missing and how these students' sense of mattering can be enhanced. If student success is to be achieved, it is timely that universities address the needs of this particular student sub-population.

\section{References}

Banning, J. H. \& Cunard, M. (1996). Assessment and redesign of the physical environment in support of student development (ACU-I Classics: Student Development). Bloomington, IN: ACU-I

Berger, J. \& Milem, J. (2000). Organizational behavior in higher education and student outcomes. In J. C. Smart (Ed.), Higher Education: Handbook of Theory and Research, (Vol. XV: pp. 268-338). New York, NY: Agathon.

Chickering, A.W. (1974). Commuting vs. residential students: Overcoming educational inequities of living off campus. San Francisco, CA: Jossey-Bass.

Creswell, J.W. (2014). Educational research: Planning, conducting, and evaluating quantitative, and qualitative research. Upper Saddle River, NJ: Merrill.

Elliott, G. C., Kao, S. \& Grant, A. (2004). Mattering: Empirical validation of a social psychological concept. Self and Identity, 3, 339-354. https://doi.org/10.1080/13576500444000119

France, M. K. (2011). Introducing the Unified Measure of University Mattering: Instrument development and evidence of the structural integrity of scores for transfer and native students. (Ph.D. 3453711), James Madison University, United States -- $\quad$ Virginia. http://ccl.idm.oclc.org/login?url=http://search.proquest.com.ccl.idm.oclc.org/docview/868185979?accountid=10 141 ProQuest Dissertations \& Theses (PQDT) database. https://doi.org/10.1037/t10693-000

Horn, L. \& Nevill, S. (2006). Profile of undergraduates in U.S. postsecondary education institutions: 2003- 04: With a special analysis of community colleges students. Retrieved fromhttp://nces.ed.gov/pubsearch/pubsinfo.asp?pubid=2006184.

Jacoby, B. (1989). The student as commuter: Developing a comprehensive institutional response (ASHE ERIC Higher Education Report No. 7). Washington, DC: School of Education and Human Development, George 
Washington University.

Jacoby, B. (2000). Why involve commuter students in learning? In Kramer, M. (Series Ed.) \& Jacoby, B. Vol. Ed.). New Directions for Higher Education: Number 109. Involving commuter students in learning, 3-12. San Francisco, CA: Jossey-Bass. https://doi.org/10.1002/he.10901

Jacoby, B. \& Garland, (2004). Strategies for enhancing commuter student success. Journal of College Student Retention: Research, Theory and Practice, 6(1), 61-79. https://doi.org/10.2190/567C-5TME-Q8F4-8FRG

Jacoby, B. \& Girrell, K.W. (1981). A model for improving services and programs for commuter students. NASPA Journal, 18(3), 36-41.

Kaufman, G., King, J. \& Verghese, G. (2014, March/April). The importance and value of our graduate students [Editorial]. MIT Faculty Newsletter, 26(4).

Keeling, R. P. (1999). A new definition of college emerges: Everything that happens to ... a (newly defined) student, in the context of a noisy visual 'datascape.' NASPA Forum, 20, 4-5.

Kinzie, J. \& Mulholland, S. (2007). Transforming physical spaces into inclusive multicultural learning environments. In S. Harper, (Ed.), Creating Inclusive College Environments for Cross Cultural Learning and Student Engagement. Washington, DC: NASPA.

Kuh, G. D. (2000). Do environments matter? A comparative analysis of the impress of different types of colleges and universities on character. Journal of College and Character. https://doi.org/10.2202/1940-1639.1277

Kuh, G. D., Kinzie, J., Schuh, J. H. \& Whitt, E. J. (2005). Student success in college: Creating conditions that matter. San Francisco, CA: Jossey-Bass.

Kuh, G. D., Kinzie, J., Buckley, J. A., Bridges, B. K. \& Hayek, J. C. (2006). What matters to student success: A review of the literature. Washington, DC: National Postsecondary Education Cooperative.

Lincoln, Y. S. \& Guba, E. G. (1985). Naturalistic inquiry. Beverly Hills, CA: Sage. https://doi.org/10.1016/0147-1767(85)90062-8

Pascarella, E. T. \& Terenzini, P. T. (2005). How college affects students: A third decade of research. San Francisco, CA: Jossey-Bass.

Rosenberg, M. \& McCullough, B. C. (1981). Mattering: Inferred significance to parents and mental health among adolescents. Research in Community and Mental Health, 2, 163-182.

Schlossberg, N. K. (1989). Marginality and mattering: Key issues in building community. In D. C. Roberts (Ed.), Designing campus activities to foster a sense of community, 5-15. New Directions for Student Services, no. 48. San Francisco, CA: Jossey-Bass. https://doi.org/10.1002/ss.37119894803

Strange, C. C. \& Banning, J. H. (2001). Educating by design: Creating campus learning environments that work. San Francisco, CA: Jossey-Bass.

Strange, C. C. \& Banning, J. H. (2015). Designing for learning: Creating campus environments for student success. San Francisco, CA: Jossey-Bass.

Strauss, A. \& Corbin, J. (1990). Basics of qualitative research. Grounded theory procedures and techniques. Newbury Park, CA: Sage.

Strauss, A. \& Corbin, J. (1998). Basics of qualitative research: Techniques and procedures for developing grounded theory (2nd ed.). Thousand Oaks, CA: Sage. 